\title{
VI ENCONTRO NACIONAL DE PAISAGISMO EM ESCOLAS DE ARQUITETURA E URBANISMO - VI ENEPEA
}

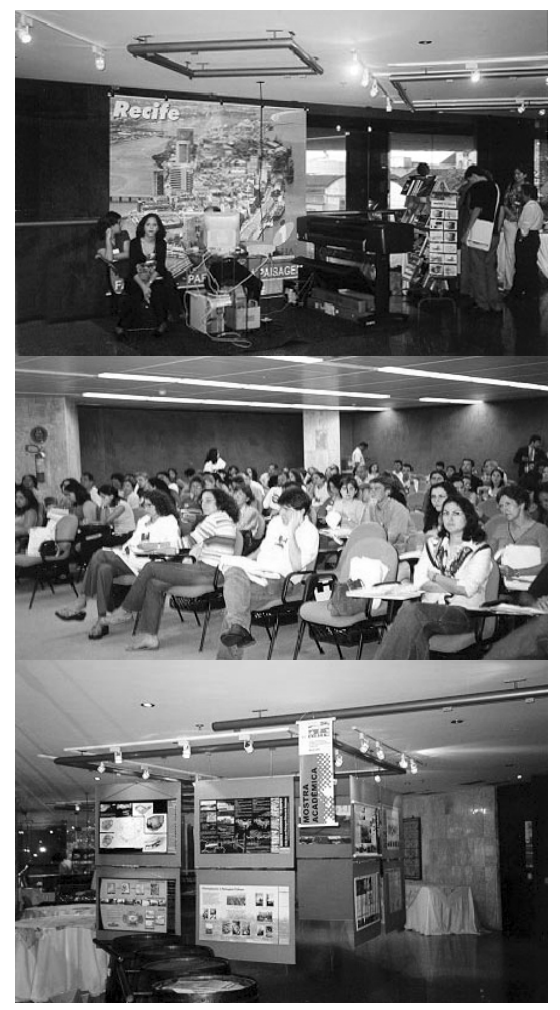

\section{Ana Rita Sá Carneiro}

Arquiteta paisagista, professora de Paisagismo da UFPE e coordenadora do Laboratório da Paisagem da UFPE.

\section{Documento}




\section{RESUMO}

O artigo avalia os resultados e explicita as atividades do VI ENEPEA - Encontro Nacional de Ensino de Paisagismo em Escolas de Arquitetura no Brasil, realizado em Recife em setembro de 2002.

O tema central "Construção da Paisagem Brasileira" foi desenvolvido em workshops, conferências, oficinas e visitas programadas e desdobrado em três subtemas: memória, permanência e projeção.

\section{ABSTRACT}

The article focuses the VI ENEPEA (Encontro Nacional de Ensino de Paisagismo em Escolas de Arquitetura - VI Brazilian National Conference about Landscape Architecture Education in Architecture Schols), wich took place in september 2002 in Recife, Pernambuco.

The main goal of the congress was to discuss Brazilian Landscape Architecture and how to do it.

The congress was developed in three different parts: conferences, workshops and visits to masterpieces of Recife's landscape architecture. 


\section{ENCONTRO NACIONAL DE PAISAGISMO \\ EM ESCOLAS DE ARQUITETURA E URBANISMO - VI ENEPEA}

\section{1 - Visão Geral do Evento}

O VI ENEPEA se realizou na cidade do Recife, no edifício do Tribunal Regional Federal e no Centro de Conservação Integrada Urbana e Territorial CECl, no período de 11 a 14 de setembro de 2002. A organização do encontro teve início já em setembro de 2000 pela equipe do Laboratório da Paisagem da UFPE. O tema central denominado Construção da Paisagem Brasileira foi desdobrado em três subtemas: memória, permanência e projeção, tendo como foco a produção de uma paisagem muitas vezes ilegível, ilegítima e ineficiente. A questão básica do debate expressou-se assim:

O que fazer com a paisagem agora?

As atividades desenvolvidas abrangeram palestras, comunicações orais, mesas-redondas, visitas técnicas às praças de Burle Marx, oficina sobre o rio Capibaribe, mostra acadêmica, concurso de estudantes, mostra de fotografias e lançamento de livros. O número de participantes ultrapassou as expectativas, chegando a 333 inscritos - superando o anterior de 200 - entre professores, estudantes (127) e profissionais de vários estados, com maior representação de Pernambuco, São Paulo, Rio de Janeiro e Santa Catarina, seguido de Alagoas e Paraíba. De 120 trabalhos enviados para as comunicações orais, 84 foram selecionados para essa modalidade, e 18 para apresentação em forma de pôster na mostra acadêmica. Esses trabalhos estarão disponíveis nos Anais do VI ENEPEA em formato de CD-ROM, em artigos de aproximadamente 10 páginas, contendo ilustrações.

O objetivo principal se pautou em discutir as diferentes expressões da paisagem nos campos do ensino, do projeto e da pesquisa. Para atender a esse objetivo, procurando explorar diferentes métodos do projeto da paisagem nas disciplinas de Paisagismo 1 e 2 da graduação, os professores do Laboratório da Paisagem do Departamento de Arquitetura e Urbanismo da UFPE montaram um programa de trabalho que teve como tema central Recife, paisagem das águas. Esse programa se iniciou no $2^{\circ}$ semestre de 2000 , indo até $0^{1}$ o semestre de 2002. As disciplinas se desenvolveram de forma complementar, trabalhando intervenções em rios, canais, lagoas, mar e mangue. Este trabalho foi apresentado no encontro e será transformado no livro Aprendendo com o Recife das águas. Outro objetivo se voltava para discutir a obra do paisagista Burle Marx, no sentido da conservação do 
patrimônio cultural do Recife, dando ênfase à paisagem histórica enfatizada na palestra de abertura, Fribvrgvm: o Parque de Nassau no Recife, e desenvolvida em trabalhos apresentados pelo Laboratório da Paisagem e pela prefeitura do Recife sobre restauração de jardins históricos.

Para a viabilização dessas atividades, o encontro obteve maior apoio financeiro da prefeitura do Recife, e em seguida da Capes, CNPq, FACEPE e da UFPE. Entre outros patrocinadores de órgãos estaduais - CEPE, FISEPE - e municipais - Fundação de Cultura da Cidade do Recife e Torre Malakoff destacamos o apoio valioso da Associação Brasileira de Cimento Portland $A B C P$, e, em um segundo momento, da CHESF, da Votorantim e da Bayer.

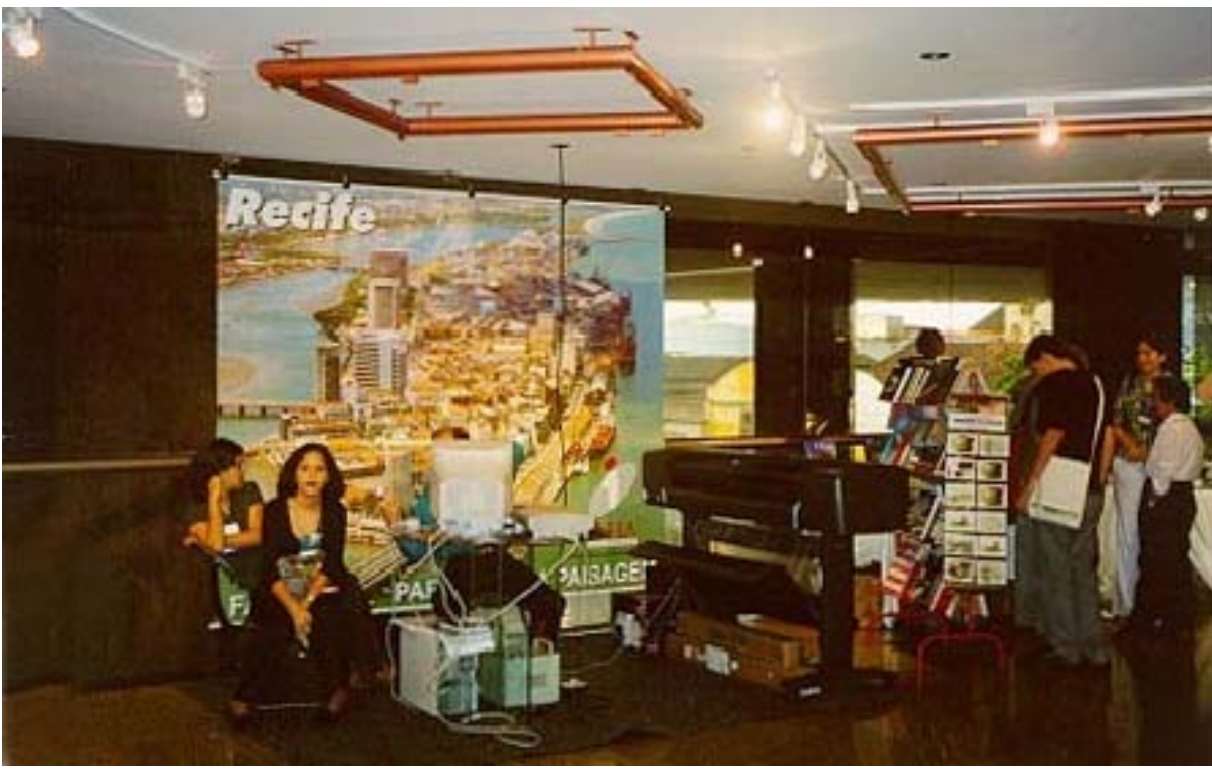

Foto 1 - Vista da exposição Fonte: Foto fornecida pela autora

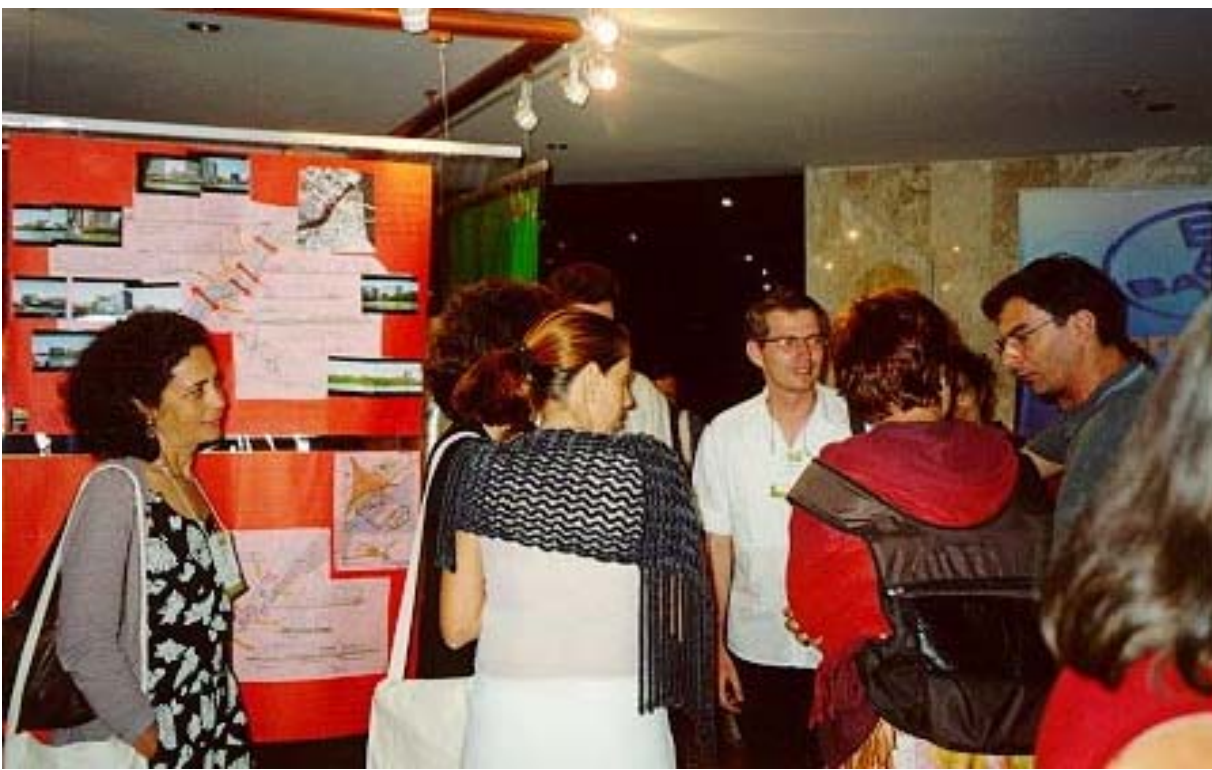

Foto 2 - Vista da exposição de trabalhos Fonte: Foto fornecida pela autora 


\section{Avaliação}

A satisfação dos participantes durante o encontro e, posteriormente, nas mensagens enviadas expressas nos cumprimentos à Comissão Organizadora do VI ENEPEA, demonstraram, em parte, que os objetivos propostos foram alcançados. $O$ fato de ter sido o primeiro do Nordeste consolidou não só o debate, mas a participação de pesquisadores, profissionais e estudantes do Norte do país. O elevado nível das pesquisas apresentadas no campo da preservação da paisagem histórica e patrimonial, seja urbana ou rural, incluindo a conservação das águas urbanas, também mostraram um avanço no conteúdo do tema e uma maior inserção no âmbito do planejamento. Notou-se uma presença significativa de técnicos de prefeituras, divulgando projetos em espaços públicos e áreas de preservação natural, o que fortalece a pesquisa na universidade e maiores possibilidades de futuras parcerias. É pertinente ressaltar não só o processo evolutivo de uma equipe coesa, na montagem do evento, como também o apoio eficiente do grupo de alunos monitores (14) nas atividades durante o encontro.

Quanto ao objetivo principal, ficou evidente que os trabalhos apresentados se voltaram mais para o projeto e a pesquisa, ao contrário dos eventos anteriores que tinham priorizado o ensino. Na intenção de explorar o método do projeto paisagístico, a proposta do Laboratório da Paisagem nas disciplinas de Paisagismo sobre as intervenções nos espaços com água não foi devidamente exposta, tendo em vista a grandeza e a relevância dessa produção. Também pouco debate ocorreu sobre a restauração dos jardins históricos de Burle Marx no Recife, o qual poderia ter sido enriquecido com a opinião de outros pesquisadores. Das atividades inicialmente propostas, as mostras de vídeos e de profissionais não aconteceram, ao mesmo tempo em que apenas três equipes se inscreveram no Concurso de Estudantes. Acreditase que os motivos da falta de participação se deveram não só à dificuldade de divulgação como também ao funcionamento de um ano letivo, com três semestres por conta da greve do ano de 2001. Além disso, a resposta dos órgãos de fomento quase às vésperas do evento, indiscutivelmente, gerou muita insegurança na definição da programação de atividades, o que impediu iniciativas que poderiam ter sido bastante empreendedoras, implicando até o risco da inviabilização do evento.

\section{2 - Palestras}

O conjunto dos temas das palestras procurou reunir um conteúdo histórico e inovador, trazendo experiências das universidades brasileira e espanhola, em especial, a Politécnica da Catalunha.

A palestra de abertura sobre o Parque de Nassau, proferida pela arquiteta Liana Mesquita, abordou os aspectos histórico, ecológico e estético da paisagem, partindo do sítio natural para o urbano do século 17, como referencial histórico do paisagismo; seguindo o percurso histórico, a palestra da professo- 
ra Maria Angélica, da UFAL, compôs um encadeamento de experiências conectando as paisagens inglesa e brasileira em jardins, cidades-jardins e cidades-parques. Focalizando as ações do urbanismo em cada um dos quatro ambientes físico-naturais que compõem o território do Recife, o professor Jan Bitoun, do curso de geografia da UFPE, provocou os participantes com indagações referentes ao imaginário e ao enaltecimento do veio estrangeiro, como uma necessidade cultural e ideológica que inibe o reconhecimento dos valores paisagísticos locais. Passou-se a detalhar um aspecto do urbano, a presença das águas urbanas, com a abordagem dos valores simbólicos e culturais dos rios pela professora Lúcia Costa, da UFRJ e, em uma escala menor, pelo paisagista e professor Luiz Vieira, da UFPE, destacando a utilização da água como elemento definidor de projetos de parques e jardins. Voltandose para o método do projeto paisagístico, as palestras dos professores espanhóis da Politécnica da Catalunha - professores Anna Zahonero, Maria Goula e Manuel Ruisánchez - trataram da importância do conhecimento dos processos naturais para o projeto dos espaços públicos em áreas urbanas e rurais, ao longo da história e da concepção de paisagem. E, finalmente, a professora Catharina Lima mostrou a importância da inclusão do usuário no projeto, tratando da pedagogia da paisagem.

\section{Avaliação}

96 As palestras levantaram questões que podem ter sido estimuladas pela pergunta central do encontro: o que fazer com a paisagem agora? , fazendo surgir indagações como: qual a paisagem que queremos? Qual conceito de paisagem queremos? Que tipo de paisagismo estamos fazendo? Em que escala estamos trabalhando? $\bigcirc$ que fazer com a universidade agora? Essas indagações geram reflexões positivas que podem direcionar novos caminhos para a evolução do debate sobre a paisagem e o paisagismo no Brasil, inclusive fornecendo elementos para serem tratados em futuros encontros e seminários.

\section{3 - Comunicações Orais}

As comunicações orais foram organizadas pela arquiteta Erika Audet e pela professora Ana Rita Sá Carneiro. Um número de 84 trabalhos estava inscrito nessa atividade, dos quais oito não foram apresentados.

As apresentações do subtema memória foram coordenadas pelo professor Silvio Macedo e pela arquiteta Ana Rosa de Oliveira; incluíram 26 trabalhos, cujo conteúdo discorreu basicamente sobre um referencial teóricometodológico, seja na pesquisa ou no projeto, e pontuando os seguintes temas: 
- Preservação do patrimônio ambiental: São Paulo

- Discussão sobre paisagem, história e memória em parques, praças e pátios em João Pessoa, Rio de Janeiro e Recife

- Aspectos do projeto urbano e traçado: Penedo, Poços de Caldas

- Casario histórico na Amazônia

- Representação e poética da paisagem: poemas pernambucanos

- Paisagem simbólica: Parque de Nassau

- Paisagem dos rios urbanos: Recife

As apresentações do subtema permanência foram coordenadas pelos professores Vera Tângari e Silvio Macedo; incluíram 26 trabalhos, cujo conteúdo discorreu basicamente sobre um referencial teórico-metodológico de pesquisa, pontuando os seguintes temas:

- Estudo dos espaços públicos e da paisagem urbana: Recife, Blumenau, João Pessoa

- $\bigcirc$ uso da água nos espaços públicos: Recife

- Turismo / Ecoturismo: Florianópolis

- Praças históricas: Belém

- Projetos / Paisagem contemporânea

- Restauração/ Revitalização dos espaços públicos e da paisagem: Brasília, Santa Catarina

- Representação simbólica da paisagem: São Luís, Recife

- Origem da paisagem: Brasília

- Identidade da paisagem: Pixaim (Alagoas)

- Modelos urbanísticos: Rio de Janeiro

- Relação homem x natureza: Natal

E as apresentações do subtema projeção foram coordenadas pelos professores Vladimir Bartalini e Emília Falcão; reuniram 32 trabalhos, abrangendo projeto (19\%), ensino (31\%) e pesquisa (50\%), tendo como principais enfoques os temas abaixo:

- Paisagem das águas: Recife

- Articulação dos espaços públicos na paisagem e elementos estruturadores: Recife, Rio de Janeiro

- Representação da paisagem: Florianópolis

- Requalificação / Reabilitação urbana: Recife, Santa Catarina

- Estudo de viabilidade para espaço público e de acessibilidade: Bauru

- Turismo: Santa Catarina

- Arborização e conforto ambiental

- Paisagem cultural

- Leituras da paisagem (ferroviária, praia): Pernambuco

- Estudo de impacto de vizinhança: Santa Catarina

- Rios urbanos na paisagem: Rio de Janeiro

- Espaços lúdicos 


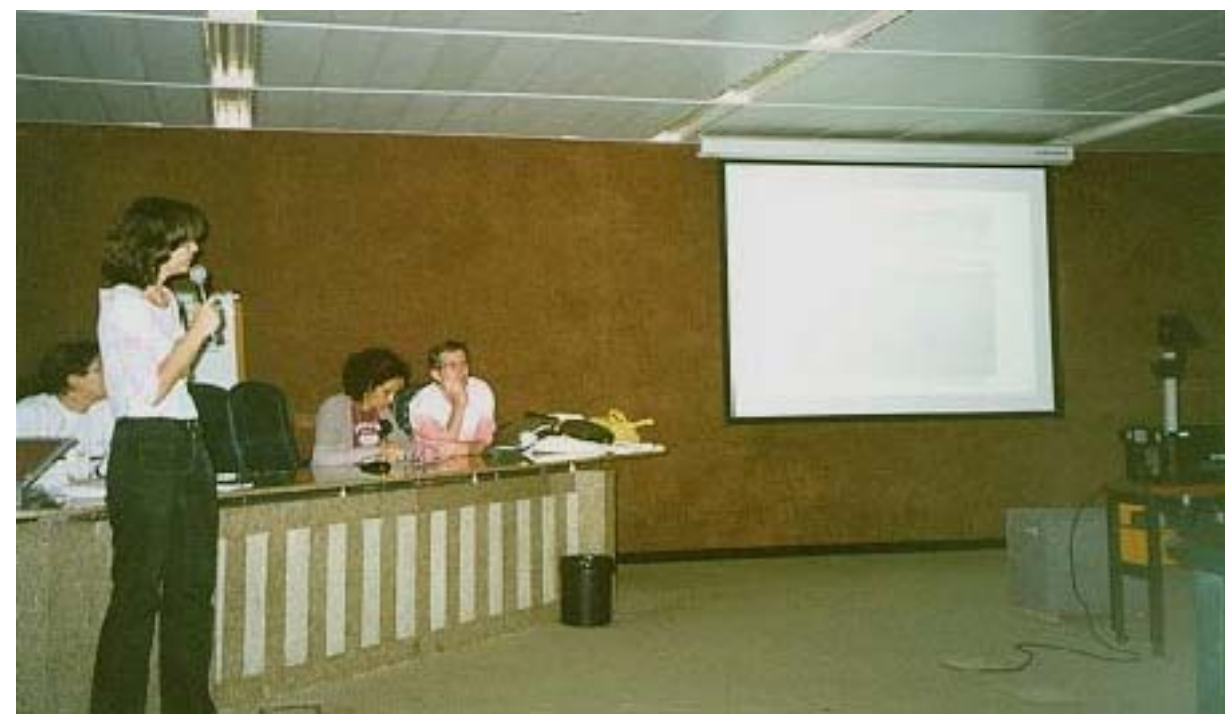

Foto 3 - Sessão temática

Fonte: Foto

fornecida pela autora

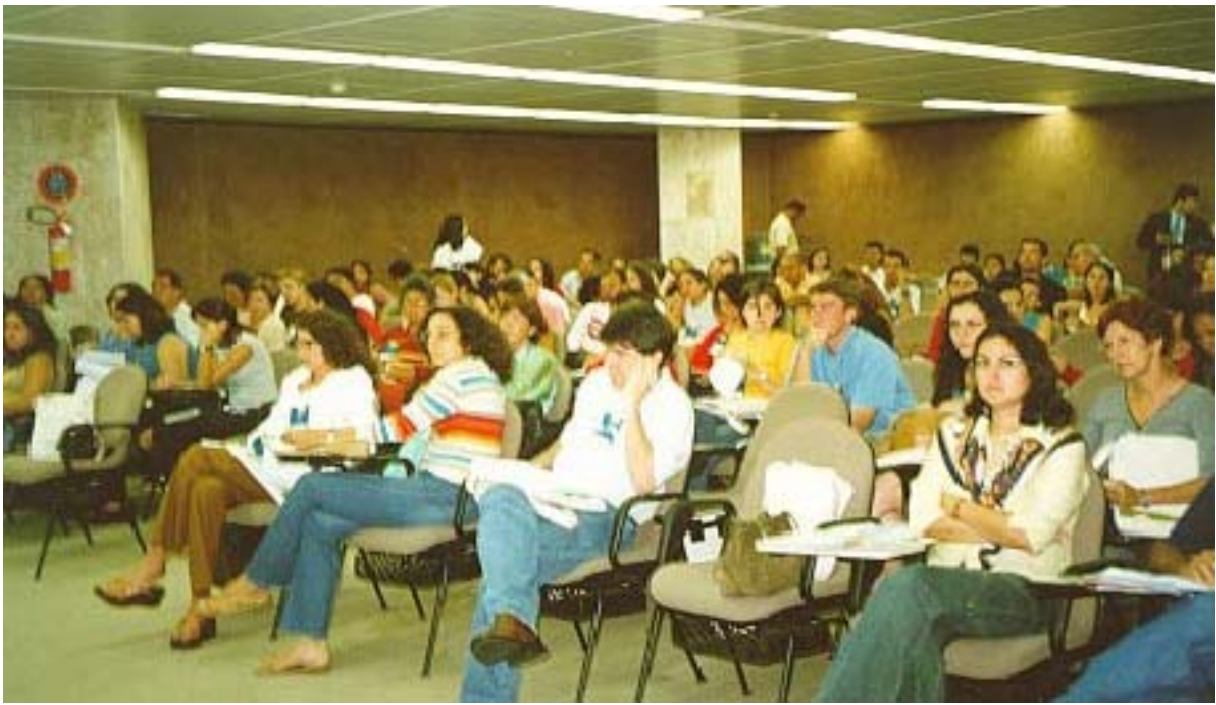

Foto 4 - Sessão temática Fonte: Foto fornecida pela autora

\section{Avaliação}

Do conjunto das comunicações orais, o subtema projeção se evidenciou mais. A temática sobre águas urbanas mereceu destaque, tanto em uma visão macro, considerando a cidade, como em uma visão micro, voltada para os espaços públicos. Também mereceu destaque a visão histórica e patrimonial da paisagem em diferentes cidades brasileiras, com expressão marcante, em cidades do Norte e Nordeste. Esses últimos trabalhos focalizavam a conservação de grandes áreas verdes, percursos, leitura da paisagem, articulação, requalificação e restauração de espaços públicos.

\section{4 - Mesas-redondas}

Duas mesas-redondas ocorreram: a primeira, com o tema $\bigcirc$ planejamento e a construção da paisagem, e, a segunda, Representação e exercício profissional. 
A primeira mesa-redonda, $\bigcirc$ planejamento e a construção da paisagem, foi coordenada pelas professoras Antonia Santamaría e Norma Lacerda, tendo como debatedores a Seplan/PCR, EMLURB/PCR, FIDEM, prefeituras de Olinda e Santo André. Foram ressaltados os seguintes aspectos nas intervenções realizadas por esses órgãos:

- Valorização dos espaços públicos, incluindo restauração de jardins históricos - praças de Burle Marx, no Recife-calçadas, margens de rios, canais, eixos urbanos e corredores culturais;

- preocupação com a poluição visual da paisagem no centro histórico;

- recuperação de matas e jardim botânico;

- sistema de parques metropolitanos.

A segunda mesa-redonda, Representação e exercício profissional, foi coordenada pelo professor Silvio Macedo, tendo como debatedores os professores Luiz Vieira e Ana Rita Sá Carneiro, levantou os seguintes aspectos:

- Conflito entre as disciplinas de paisagismo e as de planejamento arquitetônico no curso de arquitetura, como se fossem concorrentes e não complementares;

- desvinculação entre o estudo da arquitetura e o da paisagem em muitas escolas;

- visão distorcida de muitos profissionais quanto ao conteúdo do curso de paisagismo, comparando-o com o curso de jardinagem;

- aprofundamento do campo de abordagem da paisagem, diferente do paisagismo, mas considerando a multidisciplinariedade;

- falta de apoio do CNPq às pesquisas nesse campo disciplinar e da inserção da ABAP em parcerias com a universidade.

\section{Avaliação}

A primeira mesa-redonda se realizou como uma sucessão de apresentações de trabalhos das diversas instituições pelos técnicos responsáveis, sem exercer a técnica específica, o que impossibilitou um debate que sugerisse a complementação de experiências municipais e estaduais. Na segunda, ficou evidente a ausência de representantes de instituições de classe como a ABAP, que contribuísse no sentido de fundar uma associação ENEPEA, como fora sugerido no encontro anterior.

\section{5 - Visitas Técnicas}

As visitas técnicas realizadas em duas manhãs tiveram a orientação das professoras Lúcia Veras, Onilda Bezerra, Ana Maria Freitas e Cristianne Guerra e de três alunos monitores, utilizando ônibus com microfone. Essas visitas objetivaram divulgar os primeiros jardins projetados pelo paisagista Burle Marx e a relação desses espaços com a paisagem urbana. $\bigcirc$ percurso, indo do centro da cidade até a oficina Brennand, na Várzea no limite oeste, abrangeu oito espaços livres. Participaram 77 inscritos, dos quais 36 eram de 
outros estados. Informações sobre a criação das intervenções paisagistas foram fornecidas nos espaços visitados (três) e ao longo do percurso (passando por cinco deles) pelos professores apoiados pelos alunos.

\section{Avaliação}

O interesse dos participantes ficou demonstrado nos comentários e perguntas ao longo das visitas, além da preocupação em registrar os projetos de Burle Marx, confeccionando material didático. Essa oportunidade foi muito valiosa para a divulgação do potencial paisagístico dos espaços públicos e da paisagem do Recife. Algumas dificuldades surgiram relacionadas ao horário exíguo e congestionamento do trânsito.

\section{6 - Oficina}

A oficina Recife, paisagem das águas: visões do Capibaribe foi coordenada pelos professores pernambucanos: Alexandre Campello, Lúcia Veras e Antonia Santamaría, contando com a orientação dos professores espanhóis: Maria Goula, Anna Zahonero e Manuel Ruisánchez e com o apoio de dois alunos monitores. O objetivo era focar o olhar para o rio como uma linha de força da paisagem e gerador de espaços potenciais.

Reuniu 53 participantes entre alunos, técnicos e pesquisadores e transcorreu em três manhãs. Na primeira foi realizada a visita ao rio, orientada por uma metodologia de trabalho, dividindo-se o rio em nove partes e os participantes em nove grupos de cinco pessoas, as quais desenvolveriam diferentes formas de ver a paisagem, do ponto de vista do rio e considerando aspectos tais como: suporte físico, vazios, tecidos urbanos, percepção, resistências e permanências. Na segunda e terceira, em ateliê no $\mathrm{CECl}$, os grupos discutiram idéias para intervir de modo a valorizar esse recurso natural como um elemento estruturador da paisagem da cidade. Nove produtos foram apresentados em forma de painéis, com as impressões registradas livremente (palavras, desenhos, fotografias, colagens), e expostos no hall do auditório do Tribunal Regional. Esse material deverá ser analisado e sistematizado para subsidiar as ações do planejamento municipal.

\section{Avaliação}

O tempo destinado à oficina foi suficiente para explorar idéias conforme o objetivo, mas sem a pretensão de resolver os diversos problemas da conservação do rio. Já a exigüidade do espaço físico para o trabalho de ateliê dificultou a elaboração dos painéis. Por outro lado, a mostra dos painéis no hall do auditório do tribunal, sem uma apresentação oral para o público, não possibilitou uma melhor apreensão de seus conteúdos. Como contribuição ao planejamento da cidade, esse material representa esquemas imaginários criativos ou, ainda, diretrizes que poderão possibilitar um futuro projeto de intervenção. 
Foto 5 - Oficina

Fonte: Foto

fornecida pela autora

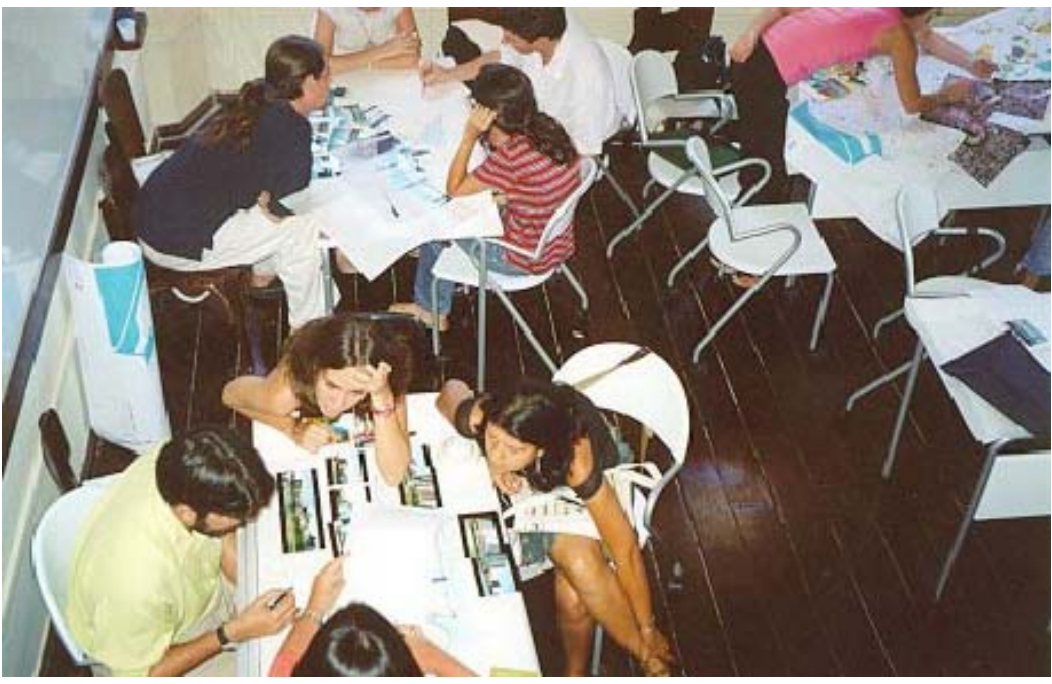

Foto 6 - Oficina

Fonte: Foto

fornecida pela autora

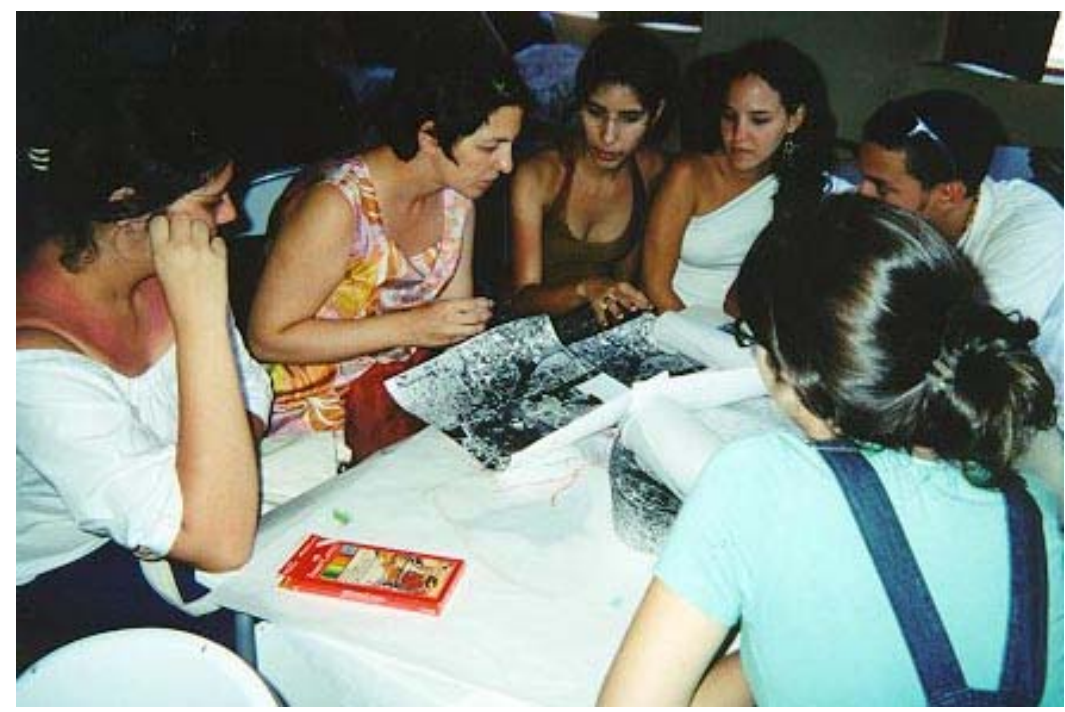

Foto 7 - Visita técnica

Fonte: Foto

fornecida pela autora

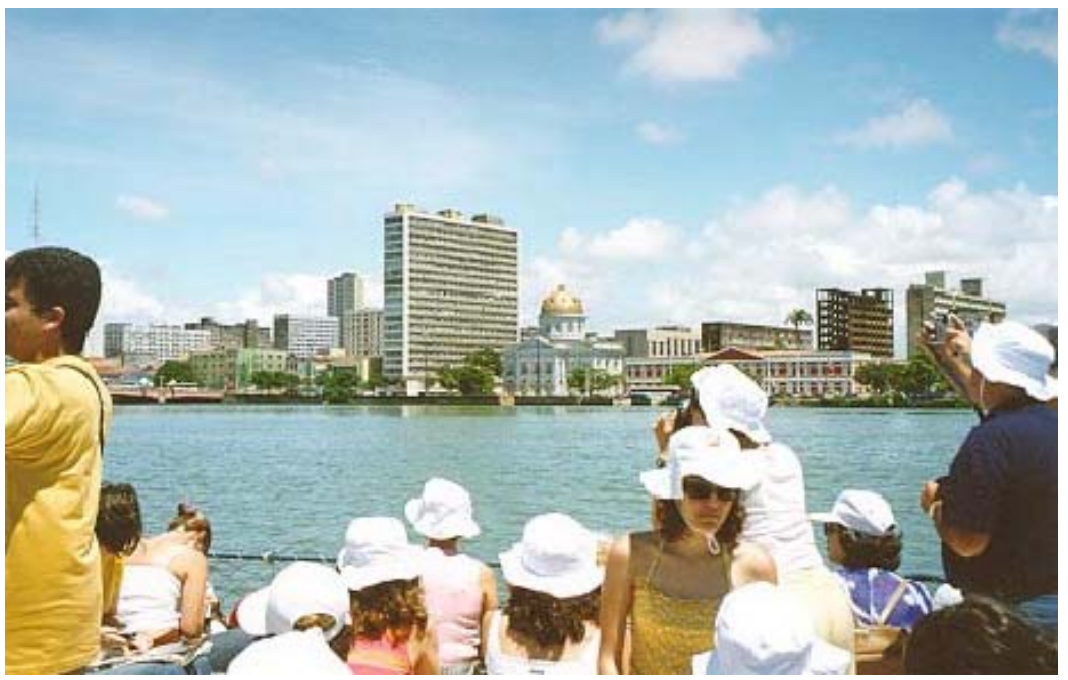




\section{7 - Mostra Acadêmica}

Para a Mostra Acadêmica, organizada pelas arquitetas Érika Audet e Luziana Medeiros e pela professora Cristianne Guerra, foram inscritos 17 trabalhos, mas apenas 14 foram expostos na forma de pôster, durante todo o evento no hall do Tribunal Regional. A localização da exposição foi bastante favorável, mas o pequeno número de trabalhos não fortaleceu essa modalidade.

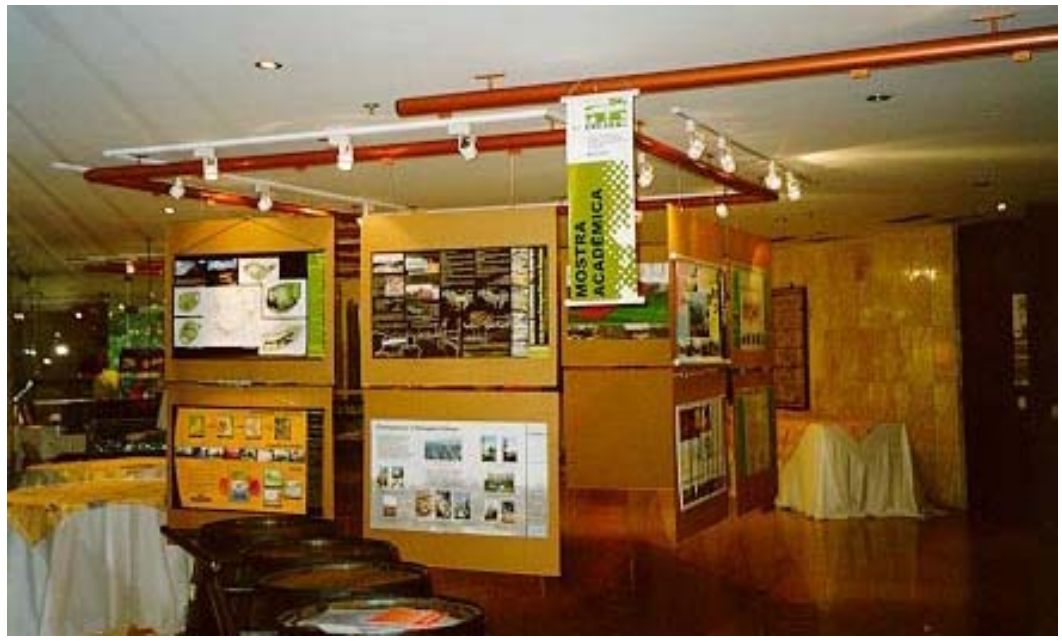

Foto 8 - Mostra acadêmica

Fonte: Foto fornecida pela autora

\section{8 - Concurso de Estudantes}

Tendo como tema llhas urbanas em paisagens imersas, o concurso recebeu a inscrição de quatro equipes de estudantes de escolas de arquitetura e urbanismo, porém apenas três, quais sejam a UFAL, a UFPE e a UFPR, concorreram enviando seus trabalhos. A comissão julgadora, formada pelos professores Lúcia Costa (UFRJ), Vladimir Bartalini (USP) e Gilson Miranda (UFPE), divulgou o resultado pela ata e considerou que os trabalhos não atingiram o nível dos objetivos requeridos, optando pela não-classificação, e atribuindo menção honrosa a todos os participantes, com premiações. Os trabalhos ficaram expostos no hall do auditório do Tribunal Regional.

\section{9 - Mostra de Fotografias}

A mostra denominada Visões da paisagem do Recife, um evento prévio, teve início com um workshop no dia 7 de setembro, orientado por cinco fotógrafos profissionais. Foram abordados cinco subtemas por um grupo de dez participantes que percorreu o centro da cidade em diversos pontos para registrar diferentes olhares da paisagem. Pelos resultados satisfatórios, um segundo workshop ocorreu nos dias 12 e 13 de setembro, reunindo 13 pessoas. Para mostrar essa produção foi confeccionado um banner que está sendo exposto nas escolas de arquitetura locais. $\bigcirc$ problema maior para a viabilização dessa atividade foi a divulgação insuficiente. 


\section{0 - Conclusões}

O VI ENEPEA inovou em conteúdo quando tratou a paisagem não só como objeto estético, no âmbito do pictórico e muitas vezes descolado da realidade, mas como parte dos problemas urbanos e ambientais. Esse aspecto se evidenciou na procura do fundamento ecológico como ponto de partida do projeto paisagístico e parceiro da função estética. $\bigcirc$ tratamento das diversas abordagens da paisagem, partindo de seu conteúdo multidisciplinar para o transdisciplinar, direciona-a da dimensão micro, ou seja, o jardim com plantas, para a dimensão macro, ou seja, a cidade e seus espaços construídos e livres. A compreensão do conceito amplo de paisagem conduz, mais imediatamente, sua incorporação nos planos e propostas do planejamento municipal e estadual como meta, como projeto a ser executado. Uma vez constatada a necessidade de uma intervenção na paisagem, percebe-se a necessidade do entendimento de seu conceito e, portanto, da existência de duas categorias de análise - a paisagem e o paisagismo.

Na sessão plenária final foi apresentada uma avaliação inicial do encontro e ficou estabelecido que o próximo, no ano de 2004, ocorrerá em Belo Horizonte e será organizado pela professora Marieta Cardoso, cujo tema abordará A compreensão dos processos naturais em intervenções na paisagem. Em anexo, seguem as cópias da divulgação do encontro nos jornais locais.

\section{Comissão Organizadora}

- Ana Rita Sá Carneiro (coordenação geral)

- Antonia Santamaría

- Alexandre Campello

- Erika Audet de Almeida

- Lúcia Veras

- Luziana Medeiros

\section{Apoio}

\section{Profissionais}

- Cristiane Guerra

- Fábio Gonçalves

- Fernanda Torres

- Onilda Bezerra

\section{Estudantes de arquitetura}

- Aline Figueirôa

- Ana Rosaly Justo

- Diogo Longhi

- Laís Pimentel 
- Lucas Coradi

- Pricylla Girão

\section{Comissão Nacional}

- Alina Santiago (UFSC)

- Ana Rosa de Oliveira (UFRS)

- Emília Falcão (UNESP/Bauru)

- Lúcia Costa (UFRJ)

- Silvio Soares Macedo (USP)

- Vera Tângari (UFRJ)

- Vladimir Bartalini (USP) 